\title{
OPTICAL COHERENCE TOMOGRAPHY;
}

RETINAL GANGLION CELL COMPLEX CHANGES ON OPTICAL COHERENCE TOMOGRAPHY AFTER PHACOEMULSIFICATION WITH INTRAOCULAR LENS IMPLANTATION.

\author{
1. FCPS (Ophthalmology) MRCS (Ed) \\ FVRO \\ Senior Registrar \\ Department of Ophthalmology \\ Lahore General Hospital, Lahore. \\ 2. FCPS \\ Senior Registrar \\ Department of Ophthalmology \\ Lahore General Hospital, Lahore. \\ 3. MBBS \\ Post Graduate Resident \\ Department of Ophthalmology \\ Mayo Hospital, Lahore.
}

Correspondence Address:

Muhammad Shaheer

Address: 48-B, Tech Town,

Satiana Road, Faisalabad.

mshaheer212@gmail.com

Article received on:

06/06/2018

Accepted for publication:

12/10/2018

Received after proof reading: 04/01/2019

\section{Muhammad Shaheer ${ }^{1}$, Arooj Amjad ${ }^{2}$, Asima Rafique ${ }^{3}$}

\begin{abstract}
Objectives: To study the changes in Ganglion Cell Complex as measured on OCT after phacoemulsification with intra ocular lens implantation. Study Design: Quasi experimental study. Place and Duration of Study: Department of Ophthalmology, Lahore General Hospital, Lahore from 1-3-2017 to 30-4-2018. Materials and Methods: Ethical approval of the study was obtained from "Ethical Review Committee" of Lahore General Hospital, Lahore. Patients presenting to the Eye OPD Lahore General Hospital were assessed for inclusion and exclusion criteria. All patients $(n=64)$ diagnosed with cataract requiring surgery were included in study. Patients having any coexisting ocular pathology hindering the OCT measurement i.e. Corneal opacity, Vitreous hemorrhage, Retinal detachment were excluded from study. Retinal Ganglion Cell Complex thickness was measured in Superior, Inferior, Supero-Nasal, Supero-Temporal, Infero-Nasal and Infero-Temporal quadrants. Besides that Signal Strength on OCT was also documented. Pre-Operatively, Visual acuity was measured and OCT performed and the findings were recorded on a designed proforma. Post-Operatively, the patients were called for followup after one month at which time Visual acuity was again measured and OCT performed and findings recorded in the proforma. All the surgeries were performed by single surgeon. Results: The thickness of Ganglion Cell Complex increased significantly $(p<0.001)$ one month after cataract surgery. Conclusion: Cataract surgery does affect the measurement of Retinal Ganglion Cell Complex thickness on OCT.
\end{abstract}

Key words: Phacoemulsification, Ganglion Cell Complex, OCT, Cataract, Retina, Signal Strength.

Article Citation: Shaheer M, Amjad A, Rafique A. Optical Coherence Tomography; Retinal ganglion cell complex changes on optical coherence tomography after phacoemulsification with intraocular lens implantation. Professional Med $\mathrm{J}$ 2019; 26(1):142-146. DOI: 10.29309/TPMJ/2019.26.01.90

\section{INTRODUCTION}

Cataract surgery is the most frequently performed ocular surgery throughout the world. ${ }^{1}$ Since its advent, cataract surgery has undergone various refinements. It started as intracapsular cataract extraction ${ }^{2}$ which was improved to extracapsular cataract extraction ${ }^{3,4}$ providing capsular support for the implantation of intra ocular lens. Phacoemulsification is the latest form of cataract surgery which is sutureless and is associated with better patient comfort, early visual and physical recovery and minimal complications. $5,6,7$

Ganglion Cell Complex (GCC) comprises of two vital layers of retina i.e. Ganglion cell layer and Inner Plexiform Layer. Modern OCT software have enabled us to measure the thickness of both these layers individually and combined as ganglion cell complex..$^{8,9}$ Macular ganglion cell thickness is subject to change with age ${ }^{10}$ and in response to various ocular diseases most important of which is glaucoma. ${ }^{11,12}$ The baseline thickness and the progression of decrease in thickness of macular ganglion cell complex is an important predictor of visual acuity outcome of the disease and its treatment. ${ }^{13}$ Besides glaucoma this vital layer can also be affected by other ocular disorders affecting retina ${ }^{14}$ and ocular surgery. ${ }^{15}$

Optical coherence tomography (OCT) is a noninvasive diagnostic imaging technology that captures micro resolution three dimensional images of retina and anterior segment. Carl Zeiss HD OCT enables to map the three dimensional images of the retina and anterior segment. Its new Panno map analysis has enabled the wide 
field structural damage assessment in glaucoma by measuring the Nerve Fiber Layer and Ganglion Cell Complex thickness. ${ }^{16}$

\section{MATERIALS AND METHODS}

Ethical approval of the study was obtained from "Ethical Review Committee" of Lahore General Hospital, Lahore. Patients presenting to the Eye OPD Lahore General Hospital were assessed for inclusion \& exclusion criteria. All patients (n-64) diagnosed with cataract and requiring surgery were included in study. Patients having any coexisting ocular pathology hindering the OCT measurement i.e. Corneal opacity, Vitreous hemorrhage, Retinal detachment were excluded from study. Retinal Ganglion Cell Complex thickness was measured by OCT (Cirrus HD OCT by Carl Zeiss) in six quadrants i.e. Superior, Inferior, Supero-Nasal, Supero-Temporal, InferoNasal and Infero-Temporal. Besides that Signal Strength on OCT was also documented. PreOperatively, Visual acuity was measured and OCT performed and the findings were recorded on a designed proforma.

After aseptic measures, opsite was applied on the eye to be operated and paracentesis was made at the limbus. Viscoelastic was injected into the anterior chamber and continuous curvilinear capsulorhexis was performed. The lens nucleus was separated from lens cortex and lens cortex was separated from lens capsule by hydro dissection and hydrodilineation. The lens was the emulsified and an intraocular lens was implanted. Post- operative steroid and antibiotic drops were given every 4 hours for two weeks and 4 times daily for the next two weeks.

The patients were called for follow-up after one month at which time Visual acuity was again measured and OCT performed and findings recorded in the proforma. All the surgeries were performed by single surgeon.

Data analysis was carried on SPSS version 22 for windows. Quantative variables were presented by their mean and standard deviation values, however the qualitative variables were presented as frequency and percentages. Paired samples t-test was applied to determine the difference between the Ganglion Cell Complex thickness of pre-surgery and one month post-surgery. $P$ value $\leq 0.05$ was considered statistically significant.

\section{RESULTS}

64 patients were included in study. Mean age of patients was $60.2 \pm 5.2$ years. $36(56.3 \%)$ patients were male and 28 (43.8\%) patients were female. 29 (45.3\%) patients had their left eye operated while right eye was operated in 35 (54.7\%) patients. 42 patients had a pre-surgery visual acuity of $6 / 60$ (65.6\%) while 22 (34.4\%) patients had a visual acuity of $6 / 36$ pre-operatively. Post operatively, $38(59.4 \%)$ patients had a visual acuity of $6 / 6$, $12(18.8 \%)$ patients had 6/9 visual acuity, visual acuity in 8 (12.5\%) patients was 6/12, 5 (7.8\%) patients had visual acuity of $6 / 18$ and one (1.6\%) patient had visual acuity of 6/36. (Table-I).

Mean Ganglion Cell Complex thickness preoperatively was $84.69 \pm 4.93$ which increased to $88.09 \pm 4.80$ one month after surgery $(p<0.001)$. Similarly, mean superior Ganglion Cell Complex thickness was83.92 \pm 5.60 before surgery which increased to $87.44 \pm 4.71$ after surgery $(p<0.001)$.

Pre-operatively, mean supero-nasal Ganglion Cell Complex thickness was $82.27 \pm 3.67$ and 85.78 \pm showing an increase in thickness $(p<0.001)$. Mean supero-temporal Ganglion Cell Complex thickness was $83.09 \pm 4.60$ before surgery which increased to $87.0 \pm 4.30$ one month after surgery $(p<0.001)$. Pre-operatively, mean inferior Ganglion Cell Complex thickness was $81.67 \pm 4.47$ which increased to $85.05 \pm 4.39$ one month after surgery $(p<0.001)$. The mean thickness in infero-nasal area was $83.06 \pm 4.87$ pre-operatively and $86.67 \pm 4.13$ after one month of surgery suggesting an increase in thickness $(p<0.001)$. In the infero-temporal area, mean preoperative Ganglion Cell Complex thickness was $82.38 \pm 4.93$ which increased post-operatively to $89.22 \pm 3.93 \quad(p<0.001)$. The mean signal strength on OCT pre-operatively was $5.41 \pm 0.49$ which increased to $8.53 \pm 0.50$ post operatively $(p<0.001)$. (Table-II).

The above results suggest that the mean 
Ganglion Cell Complex thickness increased one month after cataract surgery as well as the signal strength on OCT. The increase in Ganglion Cell Complex thickness and Signal Strength was statistically significant.

\begin{tabular}{|c|c|c|}
\hline Sr. No & Parameter & $\mathbf{n}$ \\
\hline 1 & Age in Years* & $60.2 \pm 5.2$ \\
\hline \multirow[t]{3}{*}{2} & Gender & \\
\hline & Male & $36(56.3 \%)$ \\
\hline & Female & $28(43.8 \%)$ \\
\hline \multirow[t]{3}{*}{3} & Eye Laterality & \\
\hline & Left & 29 (45.3\%) \\
\hline & Right & 35 (54.7\%) \\
\hline \multirow[t]{3}{*}{4} & Pre-Surgery Visual Acuity & \\
\hline & $6 / 60$ & $42(65.6 \%)$ \\
\hline & $6 / 36$ & 22 (34.4\%) \\
\hline \multirow[t]{6}{*}{5} & Post-Surgery Visual Acuity & \\
\hline & $6 / 6$ & $38(59.45 \%)$ \\
\hline & $6 / 9$ & $12(18.8 \%)$ \\
\hline & $6 / 12$ & $8(12.5 \%)$ \\
\hline & $6 / 18$ & $5(7.8 \%)$ \\
\hline & $6 / 36$ & $1(1.6 \%)$ \\
\hline \multicolumn{3}{|c|}{$\begin{array}{l}\text { Table-I. Distribution of age, gender, laterality and } \\
\text { visual acuity. } \\
\text { Catagorical variables were presented as Frequency and Percentage. } \\
\text { Continuous variable* was presented as Mean } \pm \text { Standard Deviation. }\end{array}$} \\
\hline
\end{tabular}

\section{DISCUSSION}

The authors present the changes in Ganglion Cell Complex thickness after cataract surgery. In this study the Ganglion Cell Complex thickness increased significantly after one month of cataract surgery. The authors believe that this increase could be due to multiple factors one of which is increased clarity of ocular media after cataract surgery which also explains the increased signal strength on OCT after cataract surgery. So this study shows that Ganglion Cell Complex thickness measurement on OCT is affected by presence of cataract or any media opacity.

Celik $E$ and associates ${ }^{17}$ have studied the effects of cataract surgery on subfoveal choroidal thickness and Ganglion Cell Complex. Their study showed an increase in Ganglion Cell Complex thickness from $85.0 \pm 4.4$ microns to $89.2 \pm 5.3$ microns. They concluded that cataract surgery does affect the measurement of Ganglion Cell Complex thickness.

Hollo $\mathrm{G}$ et $\mathrm{al}^{18}$ have compared the measurement of Ganglion Cell Complex between two software versions (6.3 \&6.12) of RTVue-100 OCT. The Ganglion Cell Complex thickness values did not differ between the two soft wares both before and after surgery. However, The Ganglion Cell Complex thickness increased after surgery as measured by both soft wares but the increase documented by software version 6.12 was statistically significant $(p<0.0001)$. Neither Focal Loss Volume (FLV) nor Global Loss Volume (GLV) differed between the software versions before and after surgery.

Nakatani $Y$ and colleagues ${ }^{19}$ have studied the Post cataract surgery changes in Ganglion Cell Complex thickness on Fourier Domain OCT. The study showed high segmentation errors in Ganglion Cell Complex thickness measurements.

\begin{tabular}{|c|c|c|c|c|}
\hline Sr. No & Parameter & Pre Cataract Surgery & $\begin{array}{c}\text { 1-Month Post } \\
\text { Cataract Surgery }\end{array}$ & P-Value \\
\hline 1 & Total Ganglion Cell Complex (GCC) Thickness & $84.69 \pm 4.93$ & $88.09 \pm 4.80$ & $<0.001$ \\
\hline 2 & Superior GCC Thickness & $83.92 \pm 5.60$ & $87.44 \pm 4.71$ & $<0.001$ \\
\hline 3 & Supero-Nasal GCC Thickness & $82.27 \pm 3.67$ & $85.78 \pm 3.59$ & $<0.001$ \\
\hline 4 & Supero-Temporal GCC Thickness & $83.09 \pm 4.60$ & $87.00 \pm 4.30$ & $<0.001$ \\
\hline 5 & Inferior GCC Thickness & $81.67 \pm 4.77$ & $85.05 \pm 4.39$ & $<0.001$ \\
\hline 6 & Infero-Nasal GCC Thickness & $83.06 \pm 4.87$ & $86.67 \pm 4.13$ & $<0.001$ \\
\hline 7 & Infero-Temporal GCC thickness & $82.38 \pm 4.93$ & $89.22 \pm 3.93$ & $<0.001$ \\
\hline 8 & Signal Strength on OCT & $5.41 \pm 0.49$ & $8.53 \pm 0.50$ & $<0.001$ \\
\hline \multicolumn{5}{|c|}{$\begin{array}{c}\text { Table-II. Changes in ganglion cell complex thickness after cataract surgery } \\
\text { Continuous variables were presented as Mean } \pm \text { Standard Deviation. } \\
\text { Paired sample T test was applied. } \mathrm{P} \text { value } \leq 0.05 \text { was considered as significant. } \\
\text { Ganglion Cell Thickness is measured in microns. }\end{array}$} \\
\hline
\end{tabular}


Multivariate analysis in the study showed that high segmentation errors were due to a poor Preoperative SSI and lenticular opacity. The eyes without segmentation errors showed a statistically significant increase in Signals Strength Index (SSI) and slight increase in Ganglion Cell Complex parameters post operatively.

Baba T and associates ${ }^{20}$ have studied the changes in Ganglion Cell Complex thickness after internal limiting membrane peeling during vitrectomy for macular hole. They noted a decrease in thickness of Ganglion Cell Complex from 95.5 \pm 6.8 microns to $84.9 \pm 10.0$ at three months and $84.2 \pm 10.8$ at six months after surgery. This decrease in Ganglion Cell Complex thickness both at three and six months was statistically significant.

Esin SS et $\mathrm{al}^{21}$ have compared the effect of intracameral anesthesia on Ganglion Cell Complex after uneventful phacoemulsification surgery. They divided the patients into two groups. One group received preservative free $1 \%$ lidocaine while the other group received sham balanced salt solution at the end of uneventful phacoemulsification surgery. Post Operatively, Both groups showed increase in Ganglion Cell Complex thickness at one week and at one month $(p<0.001)$.

Seo $\mathrm{KH}$ and associates ${ }^{22}$ have studied changes in macular Ganglion Cell Complex thickness after indocyanin green assisted internal limiting membrane peeling. The mean Ganglion cell complex thickness pre-operatively was 78.9 microns which reduced to 70.93 microns at one month and 67.64 microns at six months. This decrease in Ganglion Cell Complex thickness was statistically significant $(p<0.001)$.

Eun $\mathrm{KL}$ and collegues $^{23}$ have studied Ganglion Cell Complex thickness changes after epi retinal membrane surgery. In this study the postoperative Ganglion Cell Complex thickness was compared with the fellow normal eye after six months. The Ganglion Cell Complex thickness was significantly lower in eyes which underwent surgery i.e.71.77 \pm 10.21 as compared to the normal fellow eyes i.e. $81.69 \pm 5.33$ microns.

\section{CONCLUSION}

Presence of cataract affects the measurement of retinal ganglion cell complex thickness by Optical Coherence Tomography and cataract surgery enhances the ability of Optical Coherence Tomography to image retinal ganglion cell complex leading to an accurate measurement. Since retinal ganglion cell complex is important in the response to treatment of various ocular diseases, the authors suggest a large randomized trial in order to develop an algorithm for the assessment of retinal ganglion cell complex by OCT in phakic and pseudophakic patients.

Copyright(C) 12 Oct, 2018

\section{REFERENCES}

1. Lundstrom M, Goh PP, Henry Y, Salowi MA, Barry P, Manning $S$ et al. The changing pattern of cataract surgery indications. Ophthalmology. 2015; 122(1):3138.

2. Thompson J, Lakhani N. Cataracts. Primary Care: Clinics in office practice. 2015; 42(3):409-423.

3. Mahmud I, Kelley T, Stowell C. A proposed minimum standard set of outcome measures for cataract surgery. JAMA Ophthalmol. 2015; 133(11):1247-1252.

4. Mahmoud J, Hesam H, Mehdi K, Mohammadkarim J, Ali T, Shadi R. Endophthalmitis occurring after cataract surgery. Ophthalmology. 2016; 123(2):295-301.

5. Ewe SYP, Abell RG, Oakley CL, Lim CHL, Allen $\mathrm{PL}$ et al. A comparative cohort study of visual outcomes in femtosecond laser-assisted versus phacoemulsification cataract surgery. Ophthalmology. 2016; 123(1):178-182.

6. Catherine CG, Eric B, Anne-Sophie M, Aurelie DL, Christophe $\mathrm{C}$ et al. Incidence of postoperative endophthalmitis after cataract surgery. Ophthalmology. 2016; 123(17):1414-1420.

7. Sonia M, Peter B, Ype H, Paul R, Ulf S et al. Femtosecond laser-assisted cataract surgery versus standard phacoemulsification cataract surgery: Study from the European registry of quality outcomes for cataract and refractive surgery. Journal of Cataract \& Refractive Surgery. 2016; 42(12):1779-1790.

8. Wang $\mathrm{X}$, Jiang $\mathrm{C}, \mathrm{Ko} \mathrm{T}$, Kong $\mathrm{X}, \mathrm{Yu} \mathrm{X}$ et al. Correlation between Optic disc Perfusion and glaucomatous severity in patients with open-angle glaucoma: An optical coherence tomography angiography study. Graefe's archive for clinical and experimental ophthalmology. 2015; 253(9):1557-1564. 
9. Viquar UB, Uday KA, Ravi KY, Kalmuri S, Sirisha S et al. Ganglion cell-inner plexiform thickness of high definition optical coherence tomography in perimetric and preperimetric glaucoma. Investigative Ophthalmology \& Visual Science. 2014; 55(8):47684775.

10. Eun KL, Hyeong GY. Ganglion cell-inner plexiform layer and peripapillary retinal nerve layer thicknesses in age-related macular degeneration. Investigative Ophthalmology \& Visual Science. 2015; 56(6):39763983.

11. YuJK, Min HK, Hee YC, HanWL, MincheolS. Comparitive study of macular ganglion cell complex thickness measured by spectral-domain optical coherence tomography in healthy eyes, eyes with preperimetric glaucoma and eyes with early glaucoma. Japenese Journal of Ophthalmology. 2014; 58(3):224-251.

12. Mwanza JC, Budenz DL, Godfrey DG, Neelakantan A, Sayyad FE et al. Diagnostic performance of optical coherence tomography ganglion cell-inner plexiform thickness measurements in early glaucoma. Ophthalmology. 2014; 121(4):849-854.

13. Anraku A, Enomoto N, Takeyama A, Ito H, Tomita G. Baseline thickness of macular ganglion cell complex predicts progression of visual field loss. Graefe's archive for clinical and experimental ophthalmology. 2014; 252(1):109-115.

14. Bonin S, Tadayoni R, Erginay A, Massin P, Dupas B. Correlation between ganglion cell layer thinning and poor visual function after resolution of diabetic macular edema. Investigative Ophthalmology \& Visual Science. 2015; 56(2):978-982.

15. Park SW, Byon IS, Kim HY, Lee JE, Oum BS. Analysis of ganglion cell layer and photoreceptor layer using optical coherence tomography after idiopathic epiretinal membrane surgery. Graefe's Archive for Clinical and Experimental Ophthalmology. 2015; 253(2):207-214.

16. Francoz M, Fenolland JR, Giraud JM, Chehab HE, Sendon D et al. Reproducibility of macular ganglion cell-inner plexiform layer thickness measurement with Cirrus HD OCT in normal, hypertensive and glaucomatous eyes. British Journal of Ophthalmology. 2014; 98:322-328.

17. Celik E, Cekik B, Turkoglu EB, Dogan E, Alagoz G. Effect of cataract surgery on sub foveal choroidal and ganglion cell complex thicknesses measured by enhanced depth imaging optical coherence tomography. Clin Ophthalmol. 2016; 10:2171-2177.

18. Hollo G, Nagizadeh F, Hsu S, Filkorn T, Bausz M. Comparison of the current and a new RTVue OCT software version for detection of ganglion cell complex changes due to cataract surgery. Int Ophthalmol. 2015; 35(6):861-7.

19. Nakatani $Y$, Higashidi T, Ohkubu S, Takeda H, Sugiyama $\mathrm{K}$. Effect of cataract and its removal on ganglion cell complex thickness and peripapillary retinal nerve fiber layer thickness measurements by fourierdomain optical coherence tomography. Journal of Glaucoma. 2013; 22(6):447-455.

20. Baba T, Yamamoto S, Kimoto R, Oshitari T, Sato E. Reduction of thickness of ganglion cell complex after internal limiting membrane peeling during vitrectomy for idiopathic macular hole. Eye. 2012; 26:1173-1180.

21. Sari ES, Ermis SS, Yazici A, Koytak A, Sahin G, Kilic A. The effect of intra cameral anesthesia on macular thickness and ganglion cell-inner plexiform layer thickness after uneventful phacoemulsification surgery: prospective and randomized control trial. Graefe's Archive for Clinical and Experimental Ophthalmology. 2014; 252(3):433-439.

22. Seo KH, Yu SY, Kwak HW. Topographic changes in macular ganglion cell-inner plexiform layer thickness after vitrectomy with indocyanine green- guided internal limitimg membrane peeling for idiopathic macular hole. Retina. 2015; 35(9):1828-1835.

23. Lee EK, Yu HG. Ganglion cell-inner plexiform layer thickness after epiretinal membrane surgery. Ophthalmology. 2014; $121(8): 1579-1587$.

\section{AUTHORSHIP AND CONTRIBUTION DECLARATION}

\begin{tabular}{|c|l|l|l|}
\hline Sr. \# & \multicolumn{1}{|c|}{ Author-s Full Name } & \multicolumn{1}{|c|}{ Contribution to the paper } & Author=s Signature \\
\hline 1 & Muhammad Shaheer & $\begin{array}{l}\text { Research idea conception, } \\
\text { Performing surgery and OCT, } \\
\text { Critical review. } \\
\text { Performing surgery and OCT, } \\
\text { Data collection, Writing of } \\
\text { paper draft. } \\
\text { Data collection and analysis, } \\
\text { Literature review. }\end{array}$ \\
\hline 3 & Arooj Amjad & Asima Rafique & Arming Amjad \\
\hline
\end{tabular}

